\title{
Neurogenic bladder in twins: question
}

\author{
Z. Birsin Özçakar • Berk Burgu • F. Șemsa Altugan • Suat Fitöz • \\ Mesiha Ekim • Tarkan Soygür • Fatoș Yalçınkaya
}

Received: 11 May 2009/Revised: 2 July 2009 / Accepted: 8 July 2009/Published online: 29 July 2009

(C) IPNA 2009

\section{Case summary}

A 20-month-old boy was hospitalized at our institution with acute pyelonephritis. He had a history of two previous episodes of urinary tract infection (UTI) treated at an other center. Radiographic imaging and cystoscopy revealed no obstructive lesions such as posterior urethral valve (PUV), and dimercaptosuccinic acid (DMSA) scintigraphy was normal. Bilateral ureteral reimplantation was performed for repair of bilateral vesicoureteral reflux (VUR) when he was 12 months of age. He used antimicrobial prophylaxis irregularly during the follow-up period, and he had no constipation. Consanguinity was present between his parents. His weight, height, physical examination findings, and renal function tests were normal. Ultrasonography showed normal-sized kidneys with grade 4 hydronephrosis in the left side and dilatation in the left ureter and a mild hydronephrosis in the right kidney. The bladder wall was severely trabeculated with a thickness of $5 \mathrm{~mm}$, and a DMSA scan revealed hypoactivity in the pelvic region of the left kidney without any cortical scars in either kidneys. Voiding cystourethrography (VCUG) showed grade 4 reflux on the left side and grade 3 reflux to the right kidney.

The answer to this question can be found at http://dx.doi.org/10.1007/ s00467-009-1280-0

Z. B. Özçakar · F. Ș. Altugan · M. Ekim · F. Yalçınkaya Division of Pediatric Nephrology, Ankara University School of Medicine, Ankara, Turkey

B. Burgu $\cdot$ T. Soygür

Division of Pediatric Urology, Ankara University School of Medicine, Ankara, Turkey

S. Fitöz

Department of Radiology, Ankara University School of Medicine, Ankara, Turkey

\section{Z. B. Özçakar $(\bowtie)$}

Fakülteler Mah.Yeni Acun Sok. 11/2, Cebeci,

Ankara, Turkey

e-mail: zbozcakar@yahoo.com
His monozygotic twin was also admitted to our hospital with acute pyelonephritis and was treated accordingly. $\mathrm{He}$ had suffered from recurrent acute pyelonephritis episodes since 3 months of age. Subureteric injection was performed when he was 9 months old due to the presence of grade 3 VUR on the right side. He also had irregular antimicrobial prophylaxis and had stopped taking the drug 1 month prior to admission. Constipation was not present. His physical examination was normal. Renal ultrasound was unremarkable, with normal-sized kidneys without any dilatation. Dimercaptosuccinic acid scan showed a normal left kidney. The right kidney was inferiorly located and smaller than the left kidney; renal scars were seen in the upper and lower parts of the kidney. Voiding cystourethrography revealed grade 4 reflux to the right kidney and, interestingly, similar to his twin, a trabeculated bladder wall (Fig. 1).

\section{Questions}

1. What is your diagnosis in these patients?

2. What additional tests would you perform and how would you follow them?

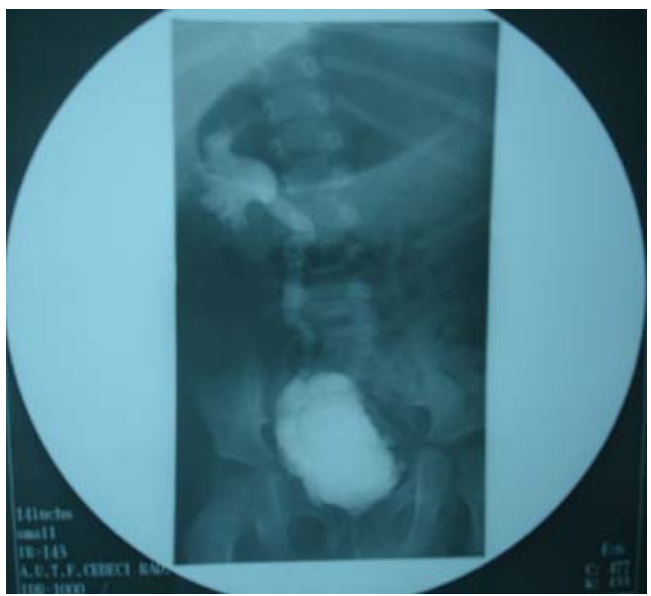

Fig. 1 Cystourethrography of patient 2 showing grade 4 reflux to the right kidney and a trabeculated bladder 